\title{
0 processo de formação e metropolização da região metropolitana de Macapá - breves reflexões
}

\author{
The process of training and metropolization of the Macapá metropolitan \\ region - brief reflections
}

\author{
João Paulo de Almeida Amorim ${ }^{I}$
}

\section{RESUMO}

Este artigo teve o objetivo de analisar a constituição da Região Metropolitana de Macapá, no Estado do Amapá, e sua relação com as ilhas do Golfão Marajoara, sob o olhar de desenvolvimento da economia local e regional, sua constituição, do ponto de vista, institucional e espacial. A metodologia empregada nessa pesquisa foi a pesquisa bibliográfica documental relativa aos conceitos de metropolização, região metropolitana, e urbanização na Amazônia. A leitura de artigos científicos, banco de dados disponíveis, livros e materiais que puderam servir de base teórica para o trabalho contribuiu para a análise e discussão dos dados e sua relação com abordagens conceituais acerca do processo de metropolização.

Palavras-chave: Metropolização; Região Metropolitana; Amazônia; Amapá

\section{ABSTRACT}

This article aimed to analyze the constitution of the Macapá Metropolitan Region, in the State of Amapá, and its relationship with the islands of Golfo Marajoara, from the perspective of development of the local and regional economy, its constitution, from the point of view, institutional and space The methodology used in this research was the documentary bibliographic research related to the concepts of metropolization, metropolitan region, and urbanization in the Amazon. The reading of scientific articles, available databases, books and materials that could serve as theoretical basis for the work contributed to the analysis and discussion of the data and its relationship with conceptual approaches about the process of metropolization.

Keywords: Metropolization; Metropolitan Region; Amazonia; Amapá

\section{INTRODUÇÃO}

O processo de metropolização na Amazônia, a partir da década de 1970, foi impulsionado pela construção de rodovias (Belém-Brasília, Cuiabá-Santarém, Transamazônica), adotadas durante o Governo Militar, através do discurso integralista e de proteção das fronteiras contra invasões externas. Esse processo é marcado pela presença de duas grandes metrópoles regionais Belém e Manaus, que polarizam as cidades sob sua órbita de influência. Corrêa (1987) já introduzia no debate, a presença de tempos diferenciados na Amazônia; uma notória diferenciação de tempos

IDoutorando em Geografia, pela Universidade Federal do Rio Grande do Norte. E-mail: joaopauloamorim30@gmail.com ORCID: https://orcid.org/0000-0002-0821-5327 
espaciais no arcabouço da rede urbana nessa região, tão marcante que pode se falar em segmentos "velhos" e novos, decorrentes da coexistência de uma natureza urbana ribeirinha, com as cidades constituídas ao longo dos rios, e as novas cidades que se desenvolvem ao longo do eixo dorsal das rodovias, ao lado da criação das áreas de colonização agrícola e dos enclaves urbanos, provocados pelos projetos minerais.

No seio dessas transformações, as cidades ribeirinhas, de um lado, e as cidades e os embriões urbanos que surgiram desses diversos processos, de outro, mostram as mudanças e permanências na rede urbana regional, e, nessas alterações, a Região Metropolitana de Macapá - RMM emerge como um "fato novo", em virtude do crescente processo de metropolização institucional que vem ocorrendo, no Brasil, nas últimas décadas.

Figura 1 - Mapa de localização da Região Metropolitana de Macapá

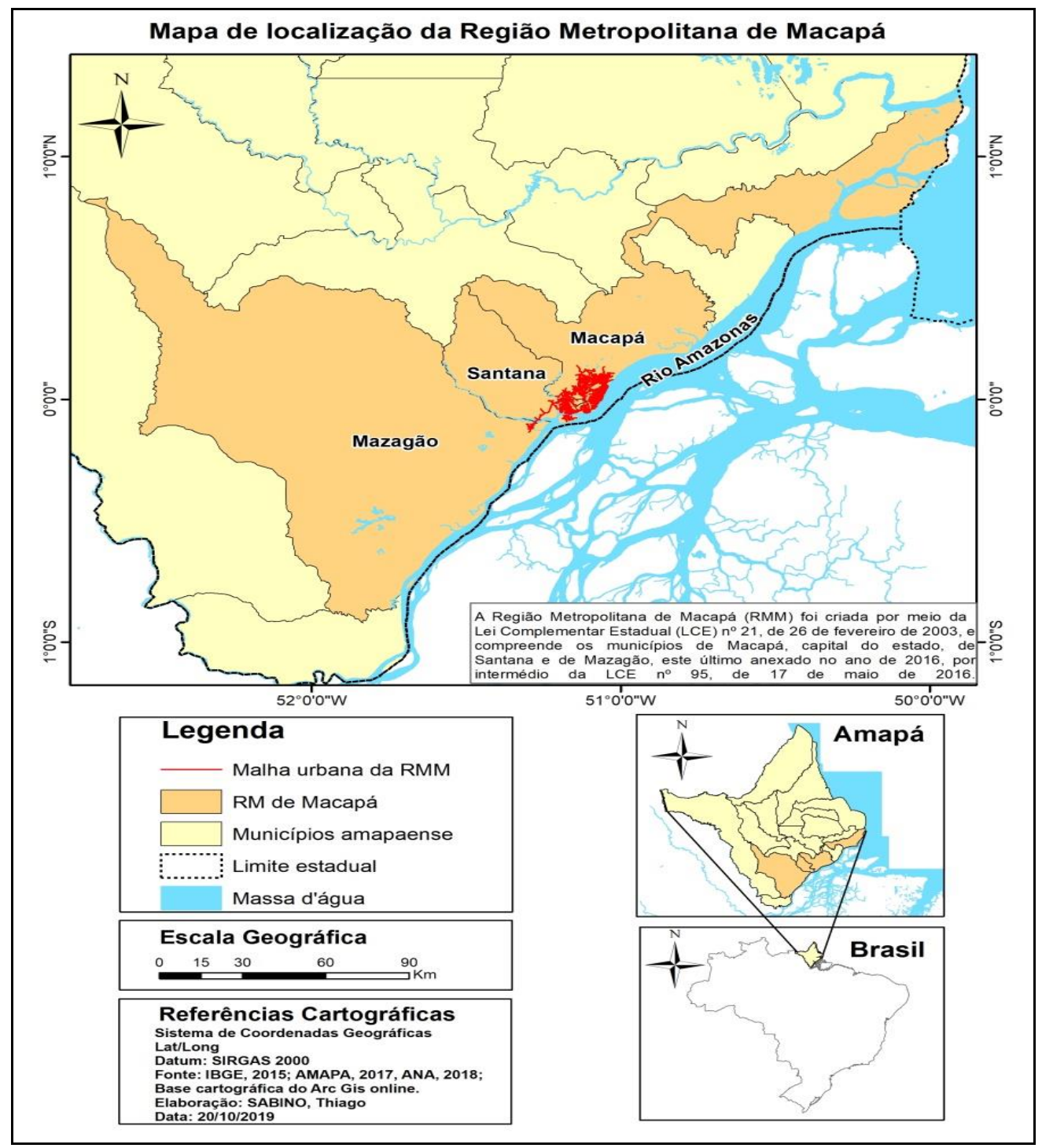

Fonte: Elaborado por Thiago Sabino. 
A RMM, localizada no Estado do Amapá (ver Figura 1), foi instituída pela Lei Complementar Estadual n. 0 21, de 26 de fevereiro de 2003, sendo constituída pelos municípios de Macapá e Santana. Recentemente foi realizada a inclusão do Município de Mazagão pela Lei Complementar Estadual no 95, de 17 de maio de 2016. Sua lógica é fortemente influenciada e tem uma relação direta com as ilhas do Golfão Marajoara, que pertencem ao Estado do Pará.

A lógica de organização do espaço da RMM está envolta na dinâmica dos rios e das florestas, apresentando uma economia interessante em escala regional e, cada vez mais, se articula ao mercado internacional por meio de produtos como o açaí, que tem se valorizado devido às suas propriedades nutritivas.

Levando em conta o processo de metropolização na Amazônia, a partir de Belém e Manaus, percebe-se a importância do diálogo da cidade com o rio, em um processo onde a conversa das diferentes temporalidades ocorrem de forma simultânea, onde a enchente e a vazante das marés produzem e reproduzem nos ribeirinhos o casamento de duas lógicas espaço-temporais diferenciadas - o tempo lento e o tempo rápido (SANTOS, 2006).

Nesse contexto, este artigo busca compreender a urbanização no espaço amazônico, considerando o território amapaense sob uma perspectiva que supere a visão de vazio demográfico e urbano atribuído a região, posto que coaduna duas temporalidades ${ }^{i}$, conexões particulares que resultam em metrópoles regionais com lógicas de produção e ocupação divergentes do processo industrial das metrópoles do centro-sul brasileiro. É nesse contexto, que se faz importante na porção mais setentrional da Amazônia, que a produção do espaço urbano da RM de Macapá surge como processo institucional, distante dos elementos característicos da metropolização no restante do país - conurbação, densidade demográfica, oferta de bens e serviços, rede de infraestrutura. Na Amazônia, elementos como o rio, a várzea e a floresta são muito presentes em sua dinâmica regional, que permite pensar novos conceitos e noções sobre o que é a metropolização e quais são os seus rebatimentos nessa região.

Como um rio que serpenteia de sua até foz até a desembocadura, passando por diferentes paisagens que saltam aos olhos do pesquisador, assim é o objetivo deste texto: serpentear pelas sinuosidades e pelos meandros dos conceitos postos sobre Metropolização e Regiões Metropolitanas, na tentativa de chegar à jusante do 
saber por meio de uma abordagem que não seja o fim, mas o espraiar da compreensão, marcando o encontro das águas do oceano com as do rio, buscando um mar de novas possibilidades, que se traduzam em noções mais próximas da realidade amazônica.

Para tanto, pretende-se, nesse primeiro momento, discutir o processo de metropolização proposto por alguns autores, em escala global, nacional e regional, em seguida, analisar as contribuições e limites de suas abordagens quando se objetiva pensar o processo de metropolização para a Amazônia, por fim, analisar a formação das Regiões Metropolitanas - RM's, no Brasil, dentre elas a RMM.

\section{O PROCESSO DE METROPOLIZAÇÃO: À MONTANTE DO PENSAMENTO}

O processo de industrialização, principalmente a partir da segunda metade do século XIX, na Europa, funcionou como motor propulsor da urbanização, através da expulsão de trabalhadores do campo para as cidades para servir como mão-de-obra para as fábricas e se consolida no espaço geográfico mundial a partir do século XX. Nesse momento histórico de crescimento vertiginoso das cidades europeias, os trabalhos pioneiros da chamada Escola de Chicago contribuíram para o pensamento do processo de Metropolização. Como exemplo de alguns trabalhos sobre o tema Geddes (1994 [1915]), em seu texto intitulado Cities in Evoltion, problematiza acerca da urbanização de Londres, em sua extensão e de como a cidade vai, pouco a pouco, absorvendo cidades menores, em uma dinâmica complexa. Para o autor, a conurbação se encontra como elemento essencial para a constituição da metrópole. Apesar da influência do Ecologismoi" em seus trabalhos ser bastante presente, teve muitas contribuições para o planejamento urbano e regional.

Burgess (1967) entende a organização e a desorganização sociais, como um processo de metabolismo: o crescimento urbano, segundo o autor, seria resultante da organização e desorganização semelhante aos processos anabólicos e catabólicos de metabolismo do corpo humano.

Gottman (1961) destaca que, no início do século XX, ocorria a tendência da produção industrial deixar as grandes cidades, desconcentrando-se mediante pressão dos custos, congestionamentos, taxas, regulamentações diversos em direção ao movimento para fora das grandes cidades. Esse processo induz ao espraiamento das 
cidades, a formação de grandes aglomerados urbanos, introduzindo a ideia de Megalópole e Nebulosa urbana, como manchas condensadas e densas de infraestrutura urbana. O articulista destaca como consequências do aglomerado e espraiamento urbano: a) relações entre desconcentração industrial, migrações e avanços tecnológicos; b) separação geográfica entre controle, gestão e produção tecnológica, com o aumento no número de empregos; c) a diminuição do emprego industrial e; d) o aumento da dispersão urbana.

Ascher (1995, p. 33) entende o processo de metropolização como a crescente concentração de "homens, atividades e riquezas nas aglomerações de várias centenas de milhares de habitantes, multifuncionais, fortemente integradas na economia internacional", fenômeno que ultrapassa a dimensão territorial das metrópoles, alcançando o modo de vida da população.

A perspectiva dos autores supracitados reside na competência em analisar, sob a ótica de cada pesquisador, os diversos elementos que podem caracterizar 0 processo de metropolização e a formação das regiões metropolitanas. Concorda-se aqui com a visão de Gottman (1961), pois o aumento da dispersão urbana no Brasil (especialmente na região Centro-Sul) tem sido resultado do acúmulo de infraestrutura, gestão, controle e indústrias por se utilizar na densidade de elementos no espaço, no entanto, apesar de seu aspecto urbano, a visão de um urbanismo e metropolização industriais possuem limitações teórico-conceituais. Nesse sentido, discute-se, a seguir, os aspectos gerais na formação das Regiões Metropolitanas no Brasil.

\section{METROPOLIZAÇÃO E FORMAÇÃO DE REGIÕES METROPOLITANAS NO} BRASIL

No campo de discussão sobre o processo de Metropolização no Brasil, Firkowski (2013) afirma que esse processo pode ser compreendido como o processo de concentração e urbanização massivas, que reforçam as funções econômicas superiores e são reforçadas em matéria de decisão, gestão e direção dos sistemas econômicos, onde alguns centros urbanos maiores tem maior sua concentração.

A autora (2001), também considera a metropolização no Brasil como um processo muito mais institucional, do que espacial de fato. Firkowski (2012) discute 
sobre a formação das regiões metropolitanas, do ponto de vista da legitimidade legal, distante da condição espacial em si, no entanto, esta proposição será abordada posteriormente.

Lencioni (2015, p. 7) considera que o processo de "metropolização do espaço" congrega características do processo de urbanização "é como se a metropolização do espaço se constituísse em uma segunda natureza da urbanização, no sentido de uma urbanização com nova essência e substância". Destarte, a autora entende que existe a emergência de um chamado pós-urbanismo, onde a transformação dos espaços metropolitanos supera a "primeira natureza urbana" industrial para um espraiamento urbano pós-industrial.

Nesse sentido, pode-se identificar como elementos da metropolização do espaço, a grande intensidade de fluxos de pessoas, mercadorias, capitais, crescimento da oferta de bens e serviços; a demanda cada vez maior de trabalho imaterial; a concentração de atividades de gestão e controle; a maior utilização de tecnologias de informação e comunicação; a grande variedade de atividades econômicas; a exacerbação da associação entre o capital financeiro, promotores imobiliários e indústria da construção; a produção da sociedade de consumo.

Brenner (2014) fala sobre uma "urbanização estendida", na qual os fenômenos e transformações socioespaciais são resultados do desenvolvimento urbano, porém, precisam de uma visão que contemple suas diferentes escalas e territórios de ação. Esse processo mostra o complexo fenômeno de crescimento e desenvolvimento das grandes aglomerações urbanas, implica também mudanças significativas no funcionamento e engendramento de novos tipos de formas urbanas. Monte-Mór (1994, p. 171) entende esse processo como uma urbanização extensiva, na qual, "se estende para além das cidades em redes que penetram virtualmente todos os espaços regionais integrando-os em malhas mundiais - representa, assim, a forma socioespacial dominante que marca a sociedade capitalista de Estado contemporânea".

O autor refere-se à Região Amazônica e, ao Centro-Oeste, como parte de uma urbanização de base urbano-industrial, no século $X X$, que irradiava a partir dos centros metropolitanos, em direção das regiões agrárias combinadas à base agroindustrial do Brasil. Apesar da relevância da discussão sobre o processo de metropolização do espaço e urbanização extensiva, coloca-se em discussão alguns 
questionamentos, no que tange a metropolização, no âmbito da Amazônia, especialmente na porção mais setentrional da região: a) a metropolização do espaço ocorre de forma igual nas porções do território nacional?; b) é possível se falar em urbanização pós-industrial na Amazônia? c) as constituições das regiões metropolitanas, no Brasil, indicam essa urbanização de forma homogênea? e; d) quais os alcances e limites de se pensar a urbanização como processo nas diferentes regiões do Brasil? Esses são algumas das questões que estão longe de esgotar a reflexão sobre o processo de metropolização, no entanto, no próximo tópico a abordagem será focada na constituição das novas Regiões Metropolitanas - RM's e o processo na qual estão inseridas, em especial a Região Metropolitana de Macapá.

O aumento expressivo, nas últimas décadas, de Regiões Metropolitanas no Brasil expressa a urbanização como motor desse processo. Os levantamentos das RM's têm sido realizados pelo Instituto Brasileiro de Geografia e Estatística - IBGE, que vêm atualizando anualmente a constituição mais recente das RM's no país.

No caso da Amazônia, o processo de urbanização se deu pelo desenvolvimento de grandes projetos minerais, com a instalação das vilas planejadas no interior da floresta - as chamadas Company townsiii - que, juntamente com a abertura das rodovias, foram os protagonistas da urbanização recente da Amazônia.

A primeira Região Metropolitana criada na região foi a de Belém - RMB, no ano de 1973, a segunda foi a Região Metropolitana de Macapá, em 2003, e a terceira foi Região Metropolitana Manaus - RMMa, em 2007, a qual contava, em 2018, com uma população de aproximadamente 2,5 milhões de habitantes.

As repercussões desse processo de metropolização no espaço regional amazônico advêm da necessidade de expansão, em direção à fronteira, da necessidade de novos padrões de acumulação de capital e da necessidade de formação do mercado de trabalho regional. Segundo dados do Censo Demográfico 2010 (IBGE, 2010), aproximadamente 72\% da população amazônica estava localizada em núcleos urbanos e, apesar de apresentar níveis de carência e precariedade quanto à existência de serviços urbanos básicos, há necessidade de enxergá-la enquanto constituinte de um modelo de urbanização voltada para a região. Atualmente, as RM's na Região Norte são identificadas pelas suas capitais - Belém (1973), Macapá (2003), Manaus (2007), Boa Vista (2007), Palmas (2013) e Porto Velho (2015). A exceção é Rio Branco, capital do Acre, cujo estado não possui este tipo de configuração urbana. 
Acerca da constituição das RM's no Norte do país observa-se a relação entre institucionalidade e espacialidade, por apresentar situações em que o processo completo de conurbação, como é o caso da RMM. Além disso, segundo Firkowski (2013, p. 41), "nem tudo que é conurbado é metropolitano", ou seja, a institucionalização das RM's, em muitos casos não respeita a lógica da espacialidade.

\section{A REGIÃO METROPOLITANA DE MACAPÁ: ENTRE O INSTITUCIONAL E O} ESPACIAL

Quando se pensa sobre o diferencial entre institucionalidade e espacialidade na constituição metropolitana é preciso deixar claro que a noção de espacialidade utilizada fundamenta-se em Firkowski (2012, p. 35), que distingue as duas noções pela sua dinâmica historicamente construída. A institucionalidade se reveste de um caráter político e legal, enquanto a espacialidade se apresenta como expressão da dimensão de processo socioespacial, ou seja, um processo que está para além da vontade dos atores políticos e de seus interesses, mas "que surge de uma dinâmica construída historicamente e por meio da inter-relação de distintos atores sociais, inclusive, mas não exclusivamente, os de natureza política".

A constituição da RMM se deu pela via institucional, não levando em conta essa construção histórica entre os municípios do estado amapaense e nem as relações com as ilhas da foz do Rio Amazonas. Sua ocupação e desenvolvimento se deram de forma mais intensa a partir da instalação do projeto de mineração da Indústria de Comércio e Mineração - ICOMI S.A., na década de 1950, no Distrito de Serra do Navio, na época pertencente ao Município de Macapá, ou seja, antes mesmo da instalação do padrão estrada-terra-firme-subsolo na região.

Além disso, o aspecto normativo/legal da instituição da RM passa pela falta de adoção de critérios para sua formação. Firkowski (2012), ao analisar a constituição das RM's do Estado do Paraná encontra, além do pressuposto de contiguidade espacial, entre parte dos municípios envolvidos no processo e de integração socioeconômica, pelo menos três critérios que se repetem em praticamente todos os casos: patamar mínimo de população, densidade e movimentos pendulares. No entanto, pode-se adicionar a essa análise o grau de conurbação entre os municípios. 
Neste momento, analisa-se aqui três elementos de composição de uma RM no Amapá: movimentos pendulares, processo de conurbação e densidade demográfica. A presença de um processo de conurbação em vias de consolidação entre Macapá e Santana e a inauguração da ponte que liga Macapá com o município de Mazagão, no início do ano de 2017, é um elemento recente nessa integração estrutural. Entretanto, dados do IBGE (2010) mostram que, apenas em torno de $10 \%$ da população total realizava movimentos pendulares nesse território (Quadro 1).

\section{Quadro 1 - Comparativo de deslocamento de pessoas que exerciam o trabalho principal} em outro município no estado do Amapá entre 2000 e 2010

\begin{tabular}{|c|c|c|}
\hline Município & Número de pessoas (2000) & Número de pessoas (2010) \\
\hline Macapá/Santana/Mazagão & 9.187 & 11.196 \\
\hline Demais municípios do Amapá & 1.819 & 5.824 \\
\hline Total da população amapaense & 477.042 & 669.076 \\
\hline
\end{tabular}

Fonte: Censo Demográfico IBGE (2000; 2010).

Santana e Macapá somam os maiores índices de deslocamento de trabalho na RMM e em todo o estado amapaense, seguido pelos municípios de Laranjal e Vitória do Jarí, que, em virtude da proximidade com o estado do Pará, projetam parte de sua mão-de-obra para os municípios vizinhos da sub-região do Vale do Jarí (AMORIM, 2016), porém, se analisarmos a população absoluta em relação ao deslocamento de pessoas entre os municípios da RM de Macapá, percebe-se uma dinâmica ainda incipiente entre os municípios.

Macapá possui maior atração em relação à Santana, por apresentar um maior número de empresas cadastradas na Área de Livre Comércio de Macapá e Santana ALCMS. O grau de integração dessas duas cidades com Mazagão se dá pela construção de duas pontes sobre os rios Anauerapucu e Matapí, substituindo os serviços de balsas para a sua instalação. A ponte sobre o Rio Matapí foi construída em 2017. Apesar do crescimento do número de condomínios ao longo das duas rodovias, e da presença de alguns empreendimentos, não se pode afirmar que existe um processo de conurbação consolidado entre os municípios, principalmente, com relação à Mazagão. 
As cidades de Macapá, Santana e Mazagão, que formam a RM, apresentam uma densidade demográfica de 62,14 hab./ $\mathrm{km}^{2}, 64,11$ hab. $/ \mathrm{km}^{2}$ e 1,30 hab./ $\mathrm{km}^{2}$, respectivamente. Todavia, se considerarmos o território da RM, a densidade declina para 28,8 hab. $/ \mathrm{km}^{2}$. Esse fato se deve a imensa extensão do Município de Mazagão, associada a um baixo contingente de habitantes. Além disso, os três municípios apresentam elevado grau de concentração urbana em seu território (Gráfico 1).

Figura 2 - Gráfico comparativo da população total do Estado do Amapá e da população da Região Metropolitana de Macapá

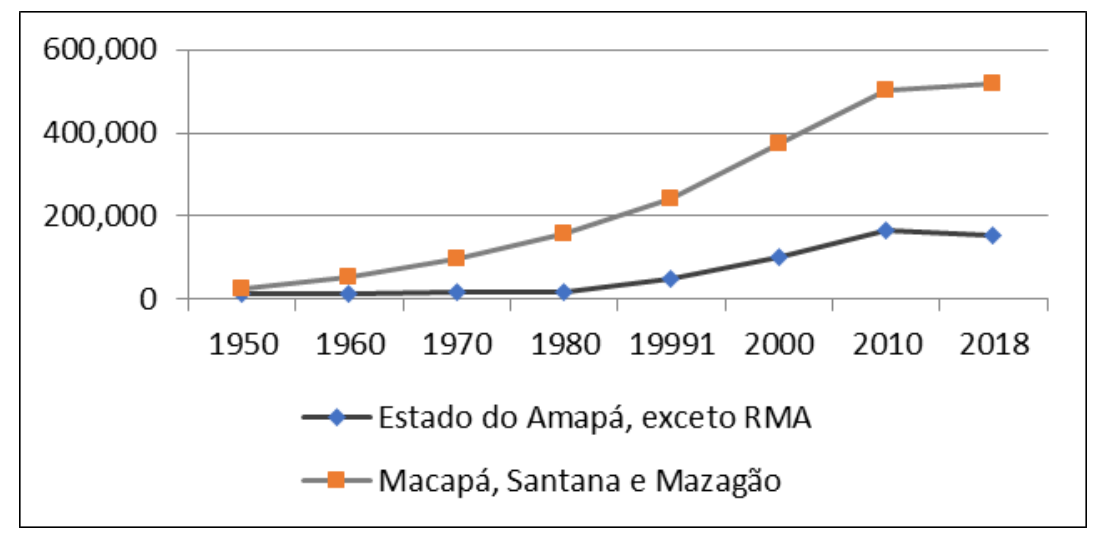

Fonte: Censo Demográfico IBGE*

*População estimada até $1^{\circ}$ de julho de 2018

O Estado do Amapá, segundo dados do IBGE, referentes à estimativa da população para 2018 possui 829.494 mil habitantes e a RMM contribui com seus três municípios um total de 516.498 habitantes, ou seja, $62,2 \%$ da população total estadual. A RMM, ainda que não possua todo seu espaço municipal conurbado, é resultado das contradições internas do capital e se coloca como desafio de se pensar seu espaço urbano sob a ótica do planejamento, pois apresenta peculiaridades no âmbito ambiental, econômico e social (ver Figura 2).

Diante dos elementos analisados, fica clara a constituição da RM de Macapá de forma normativa, sem levar em consideração a espacialidade posta neste território. Pode-se afirmar que este processo encontra-se em vias de consolidação e, não possui uma dinâmica forte o suficiente para ser considerada uma RM. No entanto, não se pode afirmar que não exista uma dinâmica urbana na região, neste sentido, apresenta-se aqui uma outra forma de enxergar essa dinâmica: a presença dos elementos naturais associados ao modo de vida urbano nessa porção mais setentrional da Amazônia. 
Figura 3 - Mapa da malha urbana da Região Metropolitana de Macapá

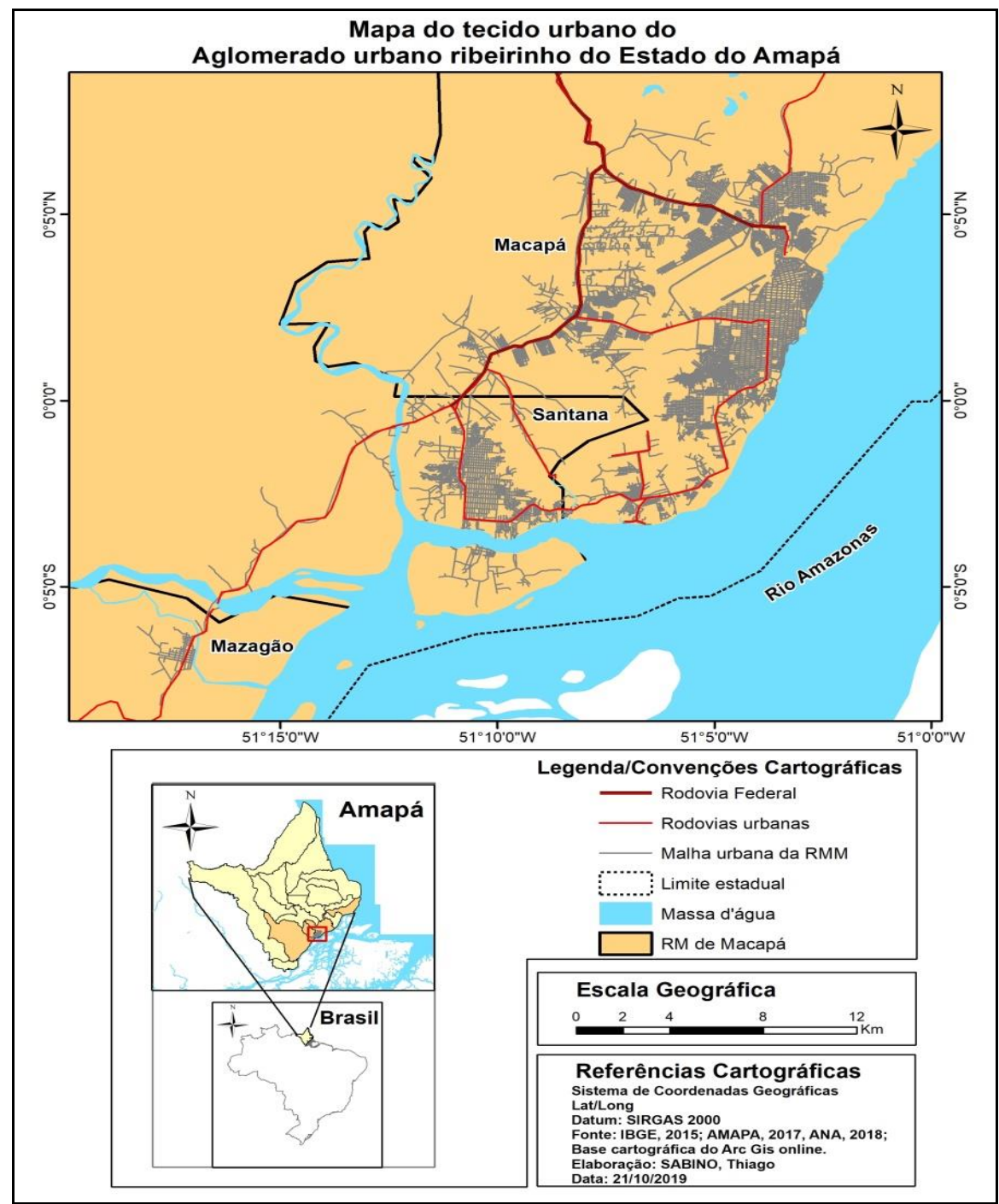

Fonte: Elaborado por Thiago Sabino.

A malha urbana da RMM denota a expansão urbana de Macapá em direção a zona Norte, com crescimento elevado de áreas de expansão espontânea, ao lado da criação de produtos imobiliários (condomínios e loteamentos) públicos e privados. 0 loteamento São José é um exemplo de loteamento público, resultado do projeto Plano de Aceleração do Crescimento - PAC, e no caso de loteamentos privados somam-se, recentemente, o empreendimento Terra Nova, Bella Vista e Cidade Jardim.

\section{PARA SE PENSAR A REGIÃo METROPOLITANA dE MACAPÁ: A NOÇÃO DE AGLOMERADO URBANO RIBEIRINHO}

Tendo como ponto de partida o reconhecimento da imensa extensão e o grau de complexidade do território brasileiro, bem como a heterogeneidade de cidades e 
do processo de urbanização, pretende-se, atrair a atenção para algumas condições peculiares da Região amazônica e de seus ordenamentos territoriais, com o objetivo de se pensar em outras possibilidades, de olhar as cidades e o processo de urbanização em curso.

Os ribeirinhos, em seu processo de ocupação ao longo da várzea dos rios amazônicos, constituíram um modo de vida bem peculiar e característico dessa região. Sua experiência histórica com os rios e com a floresta os legou práticas e valores que possibilitam a manipulação de ecossistemas extremamente delicados, por meio do desenvolvimento da pesca, da agricultura e do extrativismo. O rio, que tem importância fundamental para a vida do homem ribeirinho amazônico, corresponde a um referencial central em sua organização espacial, em seu ritmo social e no seu imaginário (mitos, lendas, crenças e cosmogonias). Nesse modo de vida, o rio não significa apenas o principal acidente geográfico, mas o meio de subsistência, de comunicação e de transporte, das pessoas, ou ainda, a mediação entre os significados e representações do imaginário social.

Em certas "Amazônias", os rios ainda funcionam como verdadeiras estradas ligando pequenas comunidades e cidades. Até a criação do ex-Território Federal do Amapá em 1943, toda a porção oriental da Amazônia (formada por uma gigantesca rede hidroviária) pertencia ao Estado do Pará. No entanto, mesmo passadas mais de seis décadas da separação territorial, ainda hoje, a base cultural do Amapá (música, dança, culinária), em sua maioria, além das relações econômicas, estão fortemente vinculadas ao estado que the deu origem.

Atualmente, em torno de $75 \%$ dos imigrantes que se dirigem ao Amapá provêm da Região Metropolitana de Belém e das Ilhas do arquipélago de Marajó, por exemplo, dos municípios de Afuá, Breves e Gurupá. Assim, grande parte dessa interação socioespacial é feita através desses caminhos fluviais, pois a outra opção de transporte é o aéreo (SANTOS, 2012), ainda não é utilizado de forma intensa pelas populações ribeirinhas.

Amorim (2016) afirma que Macapá, por ser capital, possui uma grande capacidade de polarização e centralidade, não só nos municípios da core area da Amazônia Setentrional Amapaense - ASA, como também, exerce forte atração sobre residentes das ilhas do Golfão Marajoara. Essa dinâmica mostra outra face da cidade de Macapá - seu papel de responsabilidade territorial: 
Em grandes partes do Brasil central e ocidental, pequenas cidades com poucos serviços são as únicas acessíveis para populações dispersas. Essa configuração nos levou a propor para essas pequenas cidades políticas diferenciadas e a denominação de cidade de "responsabilidade territorial" (BITOUN, 2018, p. 291).

Com esse olhar e, apesar de Macapá, centro da RM, não ser considerada uma cidade pequena, pode-se pensar a utilização da população ribeirinha da Foz do Amazonas como parte desse contexto, ao utilizar os recursos da capital amapaense e da cidade de Santana, ao verificar sua relativa proximidade, se comparada com a metrópole mais próxima, Belém/PA. Ou seja, existe um compartilhamento de "responsabilidades territoriais" do chamado Aglomerado Urbano Macapá-Santana AUMS (SANTOS, 2016), com funções essenciais de serviços, principalmente estatais, como educação e saúde, além de mercado de trabalho (no setor de comercio e serviços).

Tais cidades tornam-se importantes, independente de seus tamanhos populacionais e do papel que desempenham, pois a falta de alternativas para as populações circunvizinhas para usufruir de outros serviços, que se encontram distante de sua capital Belém, acaba por atraí-las; são, em sua maioria, ribeirinhos das ilhas do Golfão Marajoara. Essa forma de pensar as relações entre os municípios da ASA ajuda a compreender as centralidades em contextos regionais particulares, dentre eles, o papel de Macapá.

A capital amapaense se constituiu, historicamente, na utilização desses dois padrões de ocupação, sem perder de vista sua conexão com o rio e suas populações. Sua face ribeirinha denota a importância da economia regional e o elo que desenha uma passagem para uma centralidade que Trindade Jr. (2015) chama de centralidade socioterritorialiv', na qual se permite analisar a região para além de uma centralidade politica e econômica, revelando a fragmentação e urbanização difusa no território amazônico.

Tais cidades tornam-se importantes, independente de seus tamanhos populacionais e do papel que desempenham, pois a falta de alternativas para as populações circunvizinhas para usufruir de outros serviços, que se encontram distante de sua capital Belém, acaba por atrair esses, em sua maioria, ribeirinhos das ilhas do Golfão Marajoara. Essa forma de pensar as relações entre os municípios na ASA ajuda a compreender as centralidades em contextos regionais particulares, dentre eles, 0 papel de Macapá. 
O fato do município de Macapá ter se voltado para um padrão espacial estrada terra firme - subsolo, não implicou no abandono do padrão rio - várzea - floresta, pelo contrário, ambos se articulam e são imprescindíveis para o desenvolvimento da ASA como um todo [...]. É na orla fluvial da Região Metropolitana de Macapá, que estão os principais pontos de conexões para o escoamento da produção agroextrativista ribeirinha e do embarque de produtos industrializados que irão abastecer as cidades, vilas e lugarejos das ilhas da Foz do rio Amazonas (SANTOS, 2012, p. 223).

Nessa direção Costa e Cidade (2010), evidenciam que essas cidades tendem a se configurar como centros regionais (federais ou estaduais) e de centros urbanos, com melhor infraestrutura e equipados urbanos em cada região. São receptoras não só de fluxos migratórios, mas das demandas regionais de políticas públicas, como seguridade social, saúde e educação, além de constituírem referência política e administrativa para a rede urbana regional, podendo, inclusive, exercer liderança sobre as outras cidades da região e constituir a possibilidade de implantação de soluções dos problemas em conjunto, na forma de consórcios, por exemplo, atualmente, pode-se pensar na administração através da chamada Governança Interfederativav.

Santana, ao lado de Macapá, figura como centro receptor das populações ribeirinhas que, ao se deslocarem até os portos das duas cidades, aproveitam para usufruir dos serviços e equipamentos urbanos quase que ausentes nos furos e igarapés das ilhas da foz amazônica. Segundo Santos (2012), Macapá e Santana integram-se a essas ilhas, através da via fluvial, onde realizam viagens regionais em embarcações de médio porte (transporte de passageiros com uso de redes e camarotes) e de mercadorias, através dos porões dos barcos (AMARAL, 2010). Contudo, essa mesma conexão hidroviária não é vista com o Município de Mazagão. Além disso, destaca-se o transporte de produtos industrializados e commodites vindos da Zona Franca de Manaus pelo Porto de Santana, através de grandes navios e o uso de balsas, configurando a mudança no transporte multimodal (SANTOS; AMORIM, 2015).

Entre as orlas fluviais de Macapá e Santana estão os principais pontos de conexão para o escoamento da produção agroextrativista ribeirinha e do embarque de produtos industrializados que abastecem as cidades, vilas e lugarejos das ilhas da Foz do rio Amazonas (SANTOS, 2012). Além do abastecimento externo, Vitória do Jarí (sul do estado do Amapá) recebe produtos manufaturados embarcados nos navios, pelo porto de Santana, o que demonstra a capacidade de alcance espacial das duas 
principais cidades em todo o território amapaense. Os portos de Macapá e Santana conectam grande parte das ilhas do golfão marajoara ao restante da ASA, através de linhas regulares de embarcações que oferecem um intenso fluxo de passageiros entre Pará e Amapávi, com tendência de aumento, principalmente no trecho BelémSantana, devido a fatores como o aumento das passagens aéreas neste trecho.

Além dos portos de Santana, Macapá também recebe produtos regionais das ilhas do Golfão Marajoara e faz o embarque/desembarque de passageiros pelo Píer de Santa Inês, Igarapé das Mulheres e Porto de Pedrinhas, onde o produto de maior volume de negócios é a madeira. No píer de Santa Inês são feitas viagens para Afuá, Santarém, Altamira e Breves, todos do Estado do Pará, além de passageiros que embarcam para Manaus (AM), que faz passagem por Altamira. No entanto, esses navios fazem passagem pelo Porto do grego, em Santana, antes de sair do espaço amapaense. Apenas, as viagens para as ilhas próximas como Afuá e Breves fazem percurso direto do Píer.

Entre o subir e descer de passageiros das embarcações, ao longo dos portos, a entrada das rasas de açaí, do peixe fresco e da farinha de mandioca produzida, ao modo tradicional, somam-se as subidas e descidas da maré e sua força das chamadas "lançantes", pequenas embarcações lotadas de madeira, banana, macaxeira e outros produtos regionais que se agregam ao nascer do sol, em meio às feiras e ruas abarrotadas de pessoas, em busca do alimento mais "fresco" e cada vez mais "caro e raro" como o açaí, no período de entressafra. A intrusão de navios de todo o mundo presentes na orla de Macapá e Santana, em busca do precioso ouro negro, cada vez mais apreciado pelo mercado internacional e, mais ausente nas mesas dos amapaenses e paraenses tem se tornado elemento constante na paisagem quase imodificável do rio Amazonas.

Quando se analisa os elementos de uma centralidade socioterritorial, ao lado de uma vivência de uma parte importante da população da RMM construída entre a cidade e o rio pensa-se não em um espaço urbano industrial, denso, mas em um aglomerado urbano ribeirinho onde esses elementos se sobrepõem, se coadunam entre o natural e o artificial. Mesmo com a inserção cada vez maior e de difícil retrocesso na economia internacional através dos produtos da floresta, a lógica do tempo lento das marés do rio ainda é definidora de comportamentos e costumes nessa porção mais setentrional da Amazônia. 


\section{CONSIDERAÇÕES FINAIS: À JUSANTE DO PENSAMENTO}

Diante dos dados apresentados é possível concluir que, ao lado da ausência de políticas públicas de integração, pode-se notar uma carência de maior mobilidade urbana entre os municípios pertencentes à RMM, ao lado da macrocefalia urbana de Macapá e Santana, reside a baixa densidade demográfica de Mazagão e a conurbação incipiente pesam nessa condição urbana. O grau de integração na área urbana da RMM demonstra fragilidade, visto que a rede de infraestrutura necessita de maiores interações espaciais e de transportes, além de uma economia mais agregada.

Deve-se considerar a falta de um planejamento urbano integrado e a importância de Mazagão como potencial de exploração turística e cultural, com seus costumes e festas religiosas. Este município que possui uma construção histórica bastante relevante para o Estado do Amapá, se encontrava quase isolado, porém, com a construção das pontes, acredita-se que possa ser mais bem integrado e aproveitado para a economia amapaense.

Concorda-se com Firkowski (2012) quando afirma que a discussão da Região Metropolitana como institucionalidade significa, no Brasil, adjudicar ao termo um caráter mais relacionado a uma perspectiva de desenvolvimento regional do que urbano-metropolitano de fato. A constituição da RMM não priorizou o processo socioespacial, mas sim o político-institucional, ou seja, sua definição é legalmente atribuída, por força de uma lei.

Não obstante, percebe-se que cresce, de forma voraz, o número de Regiões Metropolitanas formadas por aparato legal no Brasil. A falta de relação entre o institucional e o espacial guarda, em seu bojo, uma compreensão de que, a um olhar mais atento, o distanciamento com o caráter urbano-metropolitano. No entanto, quando se busca uma visão para além desse mesmo caráter metropolitano de determinada RM, como a do Estado do Amapá, novas espacialidades se apresentam aos olhos do pesquisador. O "mundo das águas" traz em si uma dinâmica muito peculiar, rica em elementos e uma utilização da natureza muito eficaz, apesar da "lentidão" das enchentes e vazantes dos rios, furos e igarapés. Virar as costas, do ponto de vista de existência, modo de vida, economia e dinâmica dessas populações é perder um pouco da beleza do espaço, enquanto produto, meio e condição das relações sociais. 
Entende-se necessário a discussão de um planejamento urbano que incorpore as ilhas do Golfão Marajoara, em virtude de sua dinâmica econômica, regional e populacional. Pode-se somar a ideia de uma Governança Interfederativa, do ponto de vista institucional previsto legalmente no Estatuto da Metrópole, na qual haja a incorporação destes municípios pertencentes ao Pará à Região Metropolitana de Macapá, com o intuito de atender de forma mais completa e que, de fato, se constitua como uma região dotada de uma espacialidade mais próxima da realidade amazônida. Nesse sentido, como o rio encontra o mar, o conceito de Região metropolitana - urbana, industrial, densa e conurbada - possa ver na noção de Aglomerado Urbano-Ribeirinho, como realidade espacial, onde o "encontro das águas" conceitual, com seus meandros, montantes e jusantes, um novo olhar sobre o urbano na Amazônia.

\section{REFERÊNCIAS}

AMARAL, M. D. B. Dinâmicas econômicas e transformações espaciais: a metrópole de Belém e as cidades médias da Amazônia Oriental - Marabá (PA) e Macapá (AP). 2010. Tese (Doutorado em Geografia) - Faculdade de Filosofia Letras e Ciências Humanas, Universidade de São Paulo, São Paulo, SP, Brasil.

AMORIM, J. P. A. Organização espacial da sub-região de Macapá, na Amazônia Setentrional Amapaense (1990-2015). 2016. Dissertação (Mestrado em Desenvolvimento Regional) - Universidade Federal do Amapá, Macapá, Amapá, Brasil.

Agência Nacional de Transportes Aquaviários - ANTAQ. Anuário estatístico Aquaviário 2014. Disponível em: http://www.antaq.gov.br/Portal/Estatisticas_Anuarios.asp. Acesso em: 17 jul. 2015.

BRASIL. Constituição (1988). Constituição da República do Brasil. Brasília, DF: Senado, 1988.

ASCHER, F. Metápolis ou I'avenir des villes. Paris: Odile Jacob, 1995.

BITOUN, Jan. Em busca de especificidades da cidade e do urbano no Brasil. In: SERPA, A; CARLOS, A. F. A (Orgs.). Geografia urbana: desafios teóricos contemporâneos. Salvador: EDUFBA, 2018.

BRENNER, N. Teses sobre a urbanização. E-metropolis: Revista Eletrônica de Estudos Urbanos e Regionais, n. 19. ano 5, dez. 2014.

BURGESS, E. W. O crescimento da cidade: introdução a um projeto de pesquisa. In: PIERSON, D. (Org.). Estudos de Ecologia Humana. São Paulo: Martins Fontes, 1970. p. 353-368. Tradução de The Growth of the City: Na Introduction to a Research Project, (1922) 1925.

CORRÊA, R. L. A periodização da rede urbana na Amazônia. Revista Brasileira de Geografia. Rio de Janeiro, ano 49, n. 3, p. 35-64, 1987. 
COSTA, S. M. C. de. CIDADE, L. C. F. O Centro e a Centralidade na Estrutura Urbana: um debate teórico. In: Encontro Nacional dos Geógrafos. 16., Porto Alegre, Anais..., 25 a 31 de julho. Porto Alegre - RS, 2010.

FIRKOWSKI, O. Regiões metropolitanas e metrópoles: reflexões acerca das espacialidades e institucionalidades no sul do Brasil. Raega, Curitiba, n. 5, p. 23-46, 2001.

FIRKOWSKI, O. Por que as Regiões Metropolitanas no Brasil são Regiões mas não são Metropolitanas. Revista Paranaense de Desenvolvimento, Curitiba, n.122, pp.19-38, jan./jun. 2012.

FIRKOWSKI, O. Metrópoles e regiões metropolitanas no Brasil: conciliação ou divórcio. In: Território metropolitano, políticas municipais: por soluções conjuntas de problemas urbanos no âmbito metropolitano. Brasília: Ipea, 2013. pp. 23-53.

GEDDES, P. Cidades em evolução. 1915. Campinas: Papirus, 1994.

GOTTMANN, J. Megalopolis. Norwood: The Plimpton Press, 1961.

IBGE - INSTITUTO BRASILEIRO DE GEOGRAFIA E ESTATÍSTICA. Divisão regional do Brasil em regiões geográficas imediatas e regiões geográficas intermediárias. Rio de Janeiro: IBGE, 2017.

IBGE - INSTITUTO BRASILEIRO DE GEOGRAFIA E ESTATÍSTICA. Censo demográfico 2000. Dados do Arquivo de Universo. Rio de Janeiro: Secretaria de Planejamento, Orçamento e Coordenação/IBGE, 2001.

IBGE - INSTITUTO BRASILEIRO DE GEOGRAFIA E ESTATÍSTICA. Censo demográfico 2010. Disponível em: http://www.censo2010.ibge.gov.br. Acesso em: 08/06/2019.

LENCIONI, S. Urbanização difusa e a constituição de mega regiões: São Paulo-Rio de Janeiro. E-metropolis: Revista Eletrônica de Estudos Urbanos e Regionais, n. 22, ano 5, set. 2015.

MONTE-MÓR, R. L. Urbanização extensiva e lógicas de povoamento: um olhar ambiental. In: SANTOS, M. et. al. (orgs.) Território, globalização e fragmentação. São Paulo: Hucitec/Anpur, 1994, pp. 169-181.

PARK, R. E.; BURGESS, E. W.; MCKENZIE, R. O. (Ed.). The city. (1925). Chicago: University of Chicago Press, 1967.

SANTOS, M. A Natureza do Espaço: Técnica e Tempo, Razão e Emoção. 4. ed. 2. reimpr. São Paulo: Edusp, 2006.

SANTOS. E. R. C. Amazônia Setentrional Amapaense: do "mundo" das águas às florestas protegidas. 2012. Tese (Doutorado) - FCT/UNESP, Presidente Prudente, São Paulo, SP, Brasil.

SANTOS, R. V; AMORIM, J. P. A. A centralidade urbana sub-regional de Macapá-Ap e sua região de influência. In: Encontro Nacional da Associação Nacional de Pós-Graduação e Pesquisa em Planejamento Urbano e Regional, 16.; Realizado em Belo Horizonte, Anais..., de 18 a 25 de maio de 2015. Belo Horizonte - MG, 2015.

SANTOS, R. V. Estruturação e Formação do Aglomerado Urbano de Macapá e Santana na Amazônia Setentrional Amapaense. 2016. Dissertação (Mestrado em Desenvolvimento Regional) - Universidade Federal do Amapá, Macapá, Amapá, Brasil. 
TRINDADE JR, S-C. Cidades e centralidades na Amazônia: dos diferentes ordenamentos territoriais ao processo de urbanização difusa. Cidades, Presidente Prudente, v. 12, n. 21, p. 305-334, 2015.

' Os fluxos não têm a mesma rapidez. A velocidade de uma carta não é a de um telegrama, um telex, um fax. Os homens não percorrem as mesmas distâncias no mesmo tempo, dependendo dos meios com que contam (SANTOS, 2006, p. 104).

ii O Ecologismo surge como corrente de pensamento, ancorada principalmente pelo trabalho de Darwin (1895), intitulado A origem das espécies. Sobre essa corrente, ver Park, Burgess e Mackenzie (1967).

iii Sobre o processo de urbanização na Amazônia, tendo como indutor os grandes projetos minerais, vide: Trindade Jr (2009; 2011).

iv Sobre centralidade socioterritorial, vide: Trindade Jr. (2015).

${ }^{\vee}$ A governança interfederativa foi incluída no Estatuto da metrópole pela Lei $n^{\circ} 13.683$, de 2018, visando integrar funções públicas de interesse comum: compartilhamento de responsabilidades e ações entre entes da Federação em termos de organização, planejamento e execução de funções públicas de interesse comum, mediante a execução de um sistema integrado e articulado de planejamento, de projetos, de estruturação financeira, de implantação, de operação e de gestão.

vi Segundo dados da ANTAQ (2014), a projeção para o número de passageiros entre Santana e Belém até 2022 pode chegar a quase 150.000/ano e, contando com as demais linhas, esse número ultrapassa 710 mil passageiros por ano. 